\title{
(6) OPEN ACCESS \\ Treatment patterns and medication adherence of patients with glaucoma in South Korea
}

\author{
Chan Yun Kim, ${ }^{1}$ Ki Ho Park, ${ }^{2}$ Jaehong Ahn, ${ }^{3}$ Myung-Douk Ahn, ${ }^{4}$ Soon Cheol Cha, ${ }^{5}$ \\ Ho Soong Kim, ${ }^{6}$ Joon Mo Kim, ${ }^{7}$ Moon Jung Kim, ${ }^{8}$ Tae-Woo Kim, ${ }^{9}$ Yong Yeon Kim, ${ }^{10}$ \\ Ji Woong Lee, ${ }^{11}$ Sang-Woo Park, ${ }^{12}$ Yong Ho Sohn, ${ }_{1}^{13}$ Kyung Rim Sung, ${ }^{14}$ \\ Chungkwon Yoo, ${ }^{15}$ Jinhye Cha, ${ }^{16}$ Young-Joo Kim ${ }^{16}$
}

For numbered affiliations see end of article.

\section{Correspondence to} Dr Ki Ho Park, Department of Ophthalmology, Seoul National University Hospital, 28 Yongondong Chongno-gu, Seoul 110-744, Republic of Korea; kihopark@snu.ac.kr

Received 3 February 2016 Accepted 30 August 2016 Published Online First 7 March 2017
CrossMark

To cite: $\mathrm{Kim} \mathrm{CY}$, Park $\mathrm{KH}$ Ahn J, et al. Br J Ophthalmol 2017;101:801-807.
ABSTRACT

Background/aims This study aimed to investigate treatment patterns and medication adherence of glaucoma. It also identified key factors associated with non-adherence.

Methods It was a cross-sectional, observational study. Patients who use eye-drops for $\leq 2$ years were recruited at 15 eye clinics from March to November 2013. Data were collected through self-administered questionnaires and medical chart review. Medication adherence was evaluated using patients' self-report on pill count and defined as patients' administering drug for $\geq 80 \%$ of prescribed days. Medication adherence rate was calculated by dividing actual number of administration from total prescribed number of administration for 7 days. Patients whose self-reported prescription was different from total daily doses of physicians' prescription were considered as non-adherent.

Results A total of 1050 patients included, and medication adherence rate was evaluated in 1046 patients whose verification of adherence was available. Of the total, $27.4 \%$ were non-adherent, and the medication adherence rates of the total, the adherent, and the non-adherent were $90.6 \pm 17.8 \%, 96.8 \pm 5.5 \%$ and $56.6 \pm 24.7 \%$, respectively. The most commonly used medication was prostaglandin (PGA) alone and the second was combination of two-class ( $\beta$-blocker and carbonic anhydrase inhibitor (CAI)) and three-class combination of PGA, $\beta$-blocker and CAl followed. In multivariate analysis, the risk of non-adherence was 1.466 times greater in males than in females $(95 \% \mathrm{Cl}$ 1.106 to 1.943 ) and 1.328-fold greater as the daily number of administration was increased $(95 \% \mathrm{Cl} 1.186$ to 1.487$)$.

Conclusion Approximately, one-third of the patients were non-adherent, and males and increased daily number of administration were associated with nonadherence. It highlights that more systematic treatment strategies should be considered for better medication adherence, leading to effective glaucoma management.

\section{INTRODUCTION}

Glaucoma is one of the world's three major causes of blindness, which is a common disease that affects more than 70 million people worldwide. ${ }^{1}$ By 2020 , the number of patients with glaucoma is expected to reach 37 million in Asia, which represents 47\% of the world's population with glaucoma. ${ }^{1}$ In South Korea, 400000 individuals reported that they were on glaucoma therapy in 2009 alone, with an annual increase rate of $10 \%$ on average, which means that
$0.8 \%$ of the total population were being treated for glaucoma in $2009 .^{2}$ However, the actual number of patients with glaucoma is estimated to be several times higher.

Lowering intraocular pressure (IOP) has been shown to be an effective and proven treatment to prevent damage to the optic nerve. Current methods used to lower IOP are topical medication (eye-drops), laser therapy and glaucoma surgery. ${ }^{3} \mathrm{~A}$ randomised clinical study showed that glaucoma treatment using eye-drops significantly lowers the IOP and slows the progression of disease. ${ }^{4}$ To improve treatment outcomes of topical IOP-lowering agents, various factors must be considered. Medication adherence is one of the important factors that significantly affect the outcome of glaucoma treatment. ${ }^{5}$

Medication adherence plays an essential role alongside other factors such as efficacy, stability, cost of the drug and quality of life of a patient. ${ }^{6}$ Eye-drops can be inconvenient to self-administer and patients sometimes do not use them at the right times of day or in the right doses. ${ }^{7}$ According to a study conducted on 581 patients with glaucoma, only $60 \%$ of the patients used their eye-drops as prescribed by their physicians, with the most common reasons for non-adherence being forgetfulness, being busy and negligence. ${ }^{8}$ Medication adherence has been known to be affected by a number of other factors, such as age, education level, glaucoma severity, ${ }^{5}{ }^{9}$ drug class, ${ }^{6}$ dosage regimen, ${ }^{10}$ side effects, ${ }^{10}$ drug costs, ${ }^{8}$ the fear of blindness, ${ }^{11}$ disease awareness ${ }^{11}$ and amnesia. ${ }^{12}$

When medication adherence was assessed every 6 months using retrospective insurance claims data, it was found that adherence declined steadily during the 3-year observation period. ${ }^{5}$ Medication adherence in the third year was reported to be a mere $15 \%-58 \%$ depending on drug class; medication adherence of patients prescribed prostaglandins (PGAs) was the highest, followed by $\beta$-blockers, $\alpha$-antagonists and carbonic anhydrase inhibitors (CAIs) (the last two showed similar adherence). ${ }^{5}$

Although the importance of medication adherence in glaucoma treatment has been proven by various studies, only a few studies on domestic glaucoma treatment status and patient medication adherence were available, which resulted in a lack of the basic data necessary for the proper care and effective management of treatment in South Korea. Since treatment status and medication adherence are likely to be affected by a country's unique 
health insurance system, culture and social atmosphere, this study aimed to investigate those elements in a clinical setting in South Korea, identify the key factors that affect patient adherence, and ultimately provide a foundation to improve overall glaucoma treatment outcomes in South Korea.

\section{MATERIALS AND METHODS \\ Patients}

This was a non-interventional, multicentre, cross-sectional observational study conducted in 15 nationwide medical institutions located in in South Korea. The study subjects were outpatients diagnosed with glaucoma who were at least 20 years old, received treatment via eye-drops, had been treated for at least 1 month but $<2$ years and who all gave written consent to participate in the study. We excluded patients who were hospitalised for glaucoma treatment just before data collection, those who had serious or unstable medical conditions and any other patients who were determined by physicians that they should be excluded from the data collection process for any other reasons.

\section{Data collection}

During patients' regular visit, the investigators in all medical institutions selected and enrolled their study patients from those who met all the selection criteria. All questionnaires were collected from the patients via interviews in each medical institution. Data on demographic, clinical characteristics and drug habits were collected through patients' self-reported questionnaires and medical chart review.

The collected demographic data were gender, age, education level, and occupational status. The data on clinical characteristics were the following: types of glaucoma, duration of the disease, severity of the disease (Hodapp-Parrish-Anderson criteria: mild (mean deviation $\geq-6 \mathrm{~dB}$ ); moderate (mean deviation $<-6 \mathrm{~dB}$ but $>-12 \mathrm{~dB}$ ) or severe (mean deviation $\leq-12 \mathrm{~dB}$ )), family history of glaucoma, history of glaucoma surgery and presence of underlying conditions. Furthermore, the types of medications prescribed were examined to investigate the treatment patterns. Additionally, the presence or absence of assistance by another person during administration of eye-drops was recorded.

\section{Medication adherence}

Medication adherence rate was calculated using the following formula:

\section{Medication \\ adherence rate $(\%)=$

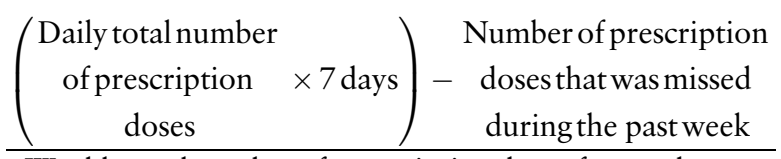

Weekly total number of prescription doses for eye drops*

\section{*Daily total number of prescription doses $\times 7$}

Total number of eye-drop administrations per week was verified by multiplying the patient-reported daily total number of prescription doses for eye-drops by 7 days; the number of times the patients missed to administer his/her eye-drops during the last 7 days was assessed through patient questionnaires. The latter was subtracted from the total number of prescription doses for a week, and the resulting value was divided by the total number of prescription doses for a week, which was then multiplied by 100 to calculate the medical adherence rate in percentage. 'Being adherent' to the prescribed medication was defined as an adherence of $\geq 80 \%$, and 'being non-adherent' was defined as adherence of $<80 \% .{ }^{13}$ Furthermore, if the data on the total number of daily doses prescribed by the physician were different from the patients' reports, the patient was considered not to be following the prescription and was therefore categorised as 'being non-adherent'.

\section{Statistical analysis}

Descriptive analysis was performed for the basic features of the data as in mean with SD for continuous variables and frequency (n) and percentage (\%) for categorical variables. For medication adherence, its differences were compared according to epidemiological characteristics and treatment patterns. Based on variable types and normality, $\chi^{2}$ test, Student's t-test and Mann-Whitney U test were used to examine differences.

To examine factors associated with non-adherence, logistic regression analysis was used. Primarily, the overall impact of the independent variables was examined by entering all independent variables into the regression model and, secondarily, backward elimination analysis was performed by adjusting gender and age as fixed variables. To evaluate the appropriateness of the backward elimination analysis model, Hosmer-Lemeshow's goodness-of-fit test was performed and the model was deemed to be appropriate at a significance level with $\mathrm{p}>0.05$. All statistical analyses were performed using PASW Statistics V.20.0 (SPSS, Chicago, Illinois, USA), and all p values obtained from statistical analyses were the results of two-sided tests, in which the statistical significance level was set at $\mathrm{p}<0.05$.

\section{RESULTS}

\section{Patient characteristics}

Of a total of 1050 patients with glaucoma, 54.8\% (575 patients) were males, $10 \%$ more males than females, and the average age was 55.1 years old ( $\mathrm{SD} \pm 12.9$ ); $73.6 \%$ (773 patients) were $<65$ years old. When the education level of the patients was divided into two groups-less than or equal to high school graduation and more than high school graduation-a similar portion of patients were found to be present in each group. About $60 \%$ patients were reported to be employed at the time of data collection. The most common type of glaucoma was normal-tension accounting for $62.4 \%$ (655 patients), followed by primary openangle glaucoma (33.2\%, 349 patients) and primary angle-closure glaucoma $(4.2 \%, 44$ patients); two patients with secondary glaucoma were also included in the study. The average disease duration from the date of diagnosis was 13.6 months ( $S D \pm 15.6)$. Patients with mild glaucoma (mean deviation $\geq-6 \mathrm{~dB}$ ) were most common, representing 54.6\% (573 individuals), and patients with moderate (mean deviation $<-6 \mathrm{~dB}$ but $>-12 \mathrm{~dB}$ ) and severe (mean deviation $\leq-12 \mathrm{~dB})$ glaucoma made up 18.1\% (190 patients) and 21\% (221 patients), respectively. Less than $10 \%$ of the total had either a family history of glaucoma or a history of glaucoma surgery, and approximately one-third of the patients had underlying diseases. Regarding medication characteristics, the average daily medication frequency for all patients was 1.9 times (SD \pm 1.1 ), the average number of prescribed eye-drops was 1.3 (SD \pm 0.5$)$ and $17.2 \%$ of the patients (181 patients) had helpers for the administration of eye-drops (table 1 ).

\section{Treatment features}

Treatment patterns were categorised according to the classes of the eye-drops administered. Administration of PGA alone was the most common treatment method, used in $43.5 \%$ of the 
Table 1 Patients' characteristics

\begin{tabular}{|c|c|c|}
\hline & $n=1050$ & $\%$ \\
\hline \multicolumn{3}{|l|}{ Sex } \\
\hline Male & 575 & 54.8 \\
\hline Female & 475 & 45.2 \\
\hline Age (years)* & $55.1 \pm 12.9$ & \\
\hline$<65$ & 773 & 73.6 \\
\hline$\geq 65$ & 277 & 26.4 \\
\hline \multicolumn{3}{|l|}{ Education level } \\
\hline$\geq$ High school graduation & 526 & 50.1 \\
\hline$<$ High school graduation & 524 & 49.9 \\
\hline \multicolumn{3}{|l|}{ Employment } \\
\hline Yes & 613 & 58.4 \\
\hline No & 437 & 41.6 \\
\hline \multicolumn{3}{|l|}{ Glaucoma types } \\
\hline Normal tension & 655 & 62.4 \\
\hline Open angle & 349 & 33.2 \\
\hline Angle closure & 44 & 4.2 \\
\hline Others & 2 & 0.2 \\
\hline Disease duration (months)* & $13.6 \pm 15.6$ & \\
\hline$\leq 12$ & 550 & 52.4 \\
\hline$>12$ & 500 & 47.6 \\
\hline \multicolumn{3}{|l|}{ Visual field defect severity } \\
\hline Mild & 573 & 54.6 \\
\hline Moderate & 190 & 18.1 \\
\hline Severe & 221 & 21.0 \\
\hline No data & 66 & 6.3 \\
\hline \multicolumn{3}{|l|}{ Glaucoma family history } \\
\hline Yes & 80 & 7.6 \\
\hline No & 970 & 92.4 \\
\hline \multicolumn{3}{|l|}{ Glaucoma surgery } \\
\hline Yes & 36 & 3.4 \\
\hline No & 1014 & 96.6 \\
\hline \multicolumn{3}{|l|}{ Underlying disease } \\
\hline Yes & 368 & 35.0 \\
\hline No & 682 & 65.0 \\
\hline Daily number of instillation* & $1.9 \pm 1.1$ & \\
\hline Number of eye-drops* & $1.3 \pm 0.5$ & \\
\hline \multicolumn{3}{|l|}{ Helper/assistant } \\
\hline No & 181 & 17.2 \\
\hline Yes & 867 & 82.6 \\
\hline
\end{tabular}

study population (457 patients); 17.1\% (180 patients) were administered both a $\beta$-blocker and a CAI, and 9.1\% (101 patients) were being treated with the three classes, PGA, $\beta$-blocker, and CAI (figure 1).

Patients with normal-tension glaucoma and primary open-angle glaucoma were most commonly prescribed PGA alone, while those with primary angle-closure glaucoma were most commonly prescribed the two classes of a $\beta$-blocker and CAI. Regardless of disease severity, disease duration (either $\leq 12$ months or $>12$ months) and the presence of underlying disease, PGA alone was the most common treatment. Among the patients who had a history of glaucoma surgery, the proportion of patients prescribed both a $\beta$-blocker and CAI together was the highest, which was followed by patients given PGA alone (figure 2).

\section{Medication adherence}

Medication adherence of 1046 patients was evaluated excluding 4 patients for whom verification of adherence was not available.
Among those, $72.6 \%$ (759 patients) were adherent, while $27.4 \%$ were non-adherent to their eye-drops. And 14.7\% (154 patients) whose self-reported number of daily instillation was not consistent with daily dose of physicians' prescription were excluded for the assessment of medication adherence rate. The mean medication adherence rates of the total, the adherent and the non-adherent were 90.6\% (SD 17.8), 96.8\% (SD 5.5) and $56.6 \%$ (SD 24.7), respectively (table 2).

Thus, there was an approximately $40 \%$ difference in the medication adherence rate between the adherent and nonadherent patients (table 2). In univariate analysis of adherent and non-adherent patients, depending on patient characteristics, males tended to be more non-adherent than females (OR 1.505, 95\% CI 1.140 to 1.987 ) (table 3).

Patients either on non-PGA monotherapy or on any combination therapy tended to be more non-adherent than those given PGA monotherapy (OR 1.953, 95\% CI 1.200 to 3.177 and OR $1.480,95 \%$ CI 1.107 to 1.979 , respectively) (table 4).

Also, the risk of non-adherence was higher as the prescribed frequency of administration was increased (OR 1.321, 95\% CI 1.182 to 1.477$)$ and also as the number of medications was increased (OR 1.603, 95\% CI 1.287 to 1.995) (table 4). In multivariate analysis using backward elimination, the risk of non-adherence was shown to be greater in males than in females by 1.466 -fold (95\% CI 1.106 to 1.943 ) and also greater as the prescribed frequency of administration was increased by 1.328-fold (95\% CI 1.186 to 1.487 ) (table 5).

\section{DISCUSSION}

Although the medication adherence of patients with glaucoma differs between reports, depending on the study patients and the methods of measurement, it is known to be low because glaucoma typically has no clear symptoms until it develops enough to reach its last stages. ${ }^{1}$ Therefore, an increase in medication adherence is regarded as an important factor for the better management of glaucoma. In this multicentre study, we aimed to investigate which factors influence medication adherence among patients with glaucoma in South Korea.

According to our results, the medication adherence rate of the patients with glaucoma in South Korea was 90.6 $\pm 17.8 \%$, and patients with $<80 \%$ medication adherence (non-adherent patients) made up about $30 \%$ of the study population. Hence, medication adherence of patients with glaucoma in South Korea appears to be relatively good when compared with that in foreign countries as reported to be $15 \%-58 \% .^{5}$ And, it could be partially explained by the relatively good insurance coverage and accessibility; also, however, we used self-reported questionnaires to quantify medication adherence rate, which may play a role to bring these results.

In this study, the risk of non-adherence was found to be higher among males and as the daily prescribed frequency of eye-drop administration increased. The latter result is consistent with the findings of a study, which showed that medication adherence of patients administered PGA alone was the highest; that study used retrospective insurance claims for prescription eye-drop refills, measured every 6 months. ${ }^{5}$ Therefore, continuous education and efforts to simplify the drug administration method are needed for those who are at increased risk to enhance the therapeutic effect of glaucoma treatment and improve medication adherence.

This study did not show differences in adherence by type of glaucoma. It is known that patients with angle-closure glaucoma would be more adherent to their medication regimens given the fact that angle-closure glaucoma is often accompanied by 


\section{Clinical science}

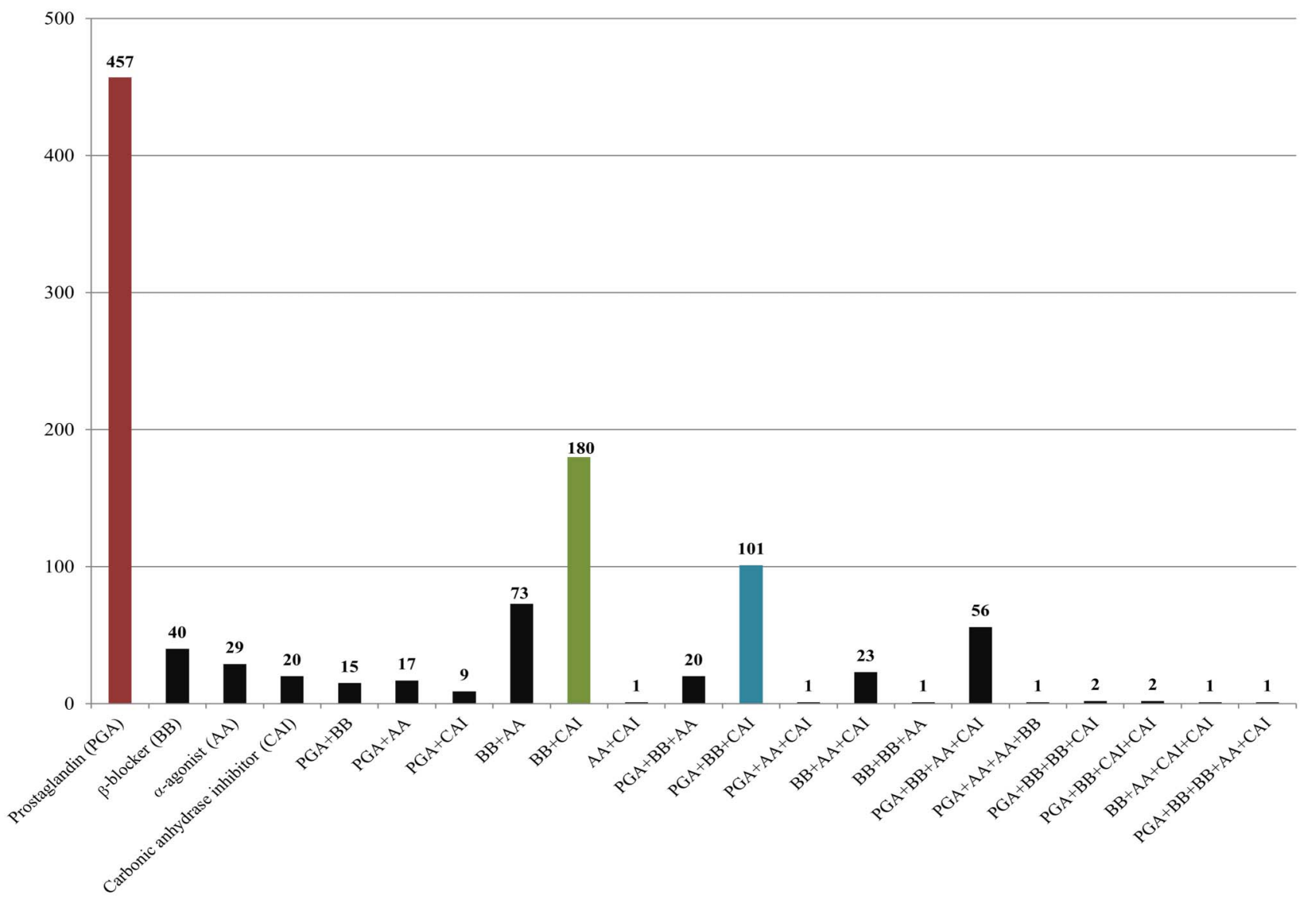

Figure 1 Treatment patterns.

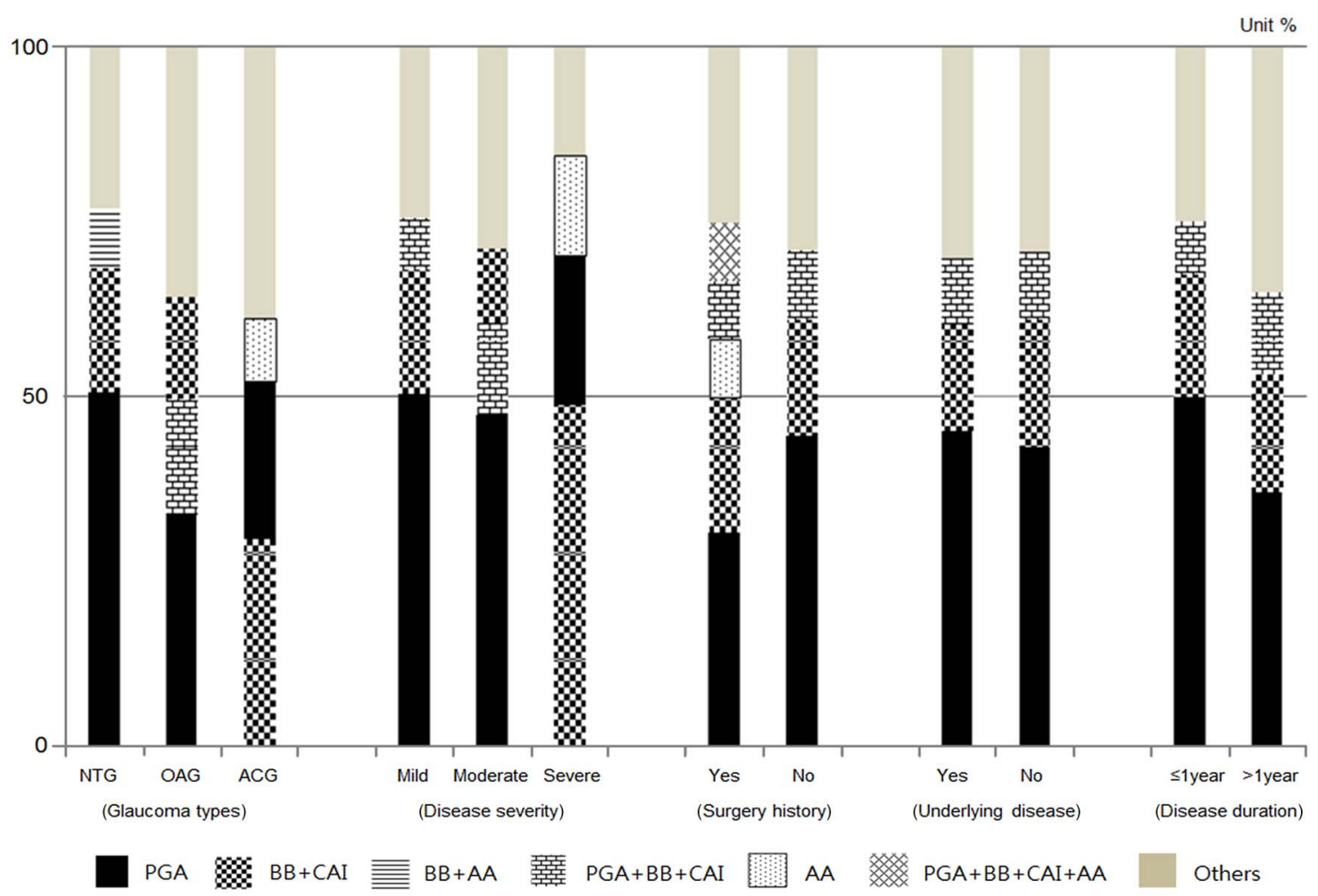

Figure 2 Top 3 prescribed glaucoma medication by patients' clinical characteristics. 
Table 2 Adherence to prescribed glaucoma medications

\begin{tabular}{|c|c|c|c|c|}
\hline & \multirow[b]{2}{*}{ Total patients* } & \multirow[b]{2}{*}{ Adherent patientst } & \multicolumn{2}{|l|}{ Non-adherent patients } \\
\hline & & & Absolute non-adherent $\ddagger$ & Misconception§ \\
\hline $\mathrm{n}(\%)$ & 1046 & $759(72.6)$ & $133(12.7)$ & $154(14.7)$ \\
\hline Mean \pm SD & $90.6 \pm 17.8$ & $96.8 \pm 5.5$ & $56.6 \pm 24.7$ & NA \\
\hline Minimum, maximum & 0,100 & $82.1,100$ & $0,78.6$ & NA \\
\hline
\end{tabular}

Table 3 Medication non-adherence according to patients' characteristics

\begin{tabular}{|c|c|c|c|c|}
\hline Variables & Adherent $(n=759)$ & Non-adherent $(n=287$ ) & OR & p Value \\
\hline \multicolumn{5}{|l|}{ Sex } \\
\hline Male & $395(68.9)$ & $178(31.1)$ & 1.505 (1.140 to 1.987$)$ & 0.004 \\
\hline Female & $364(77.0)$ & $109(23.0)$ & 1 & \\
\hline \multicolumn{5}{|l|}{ Age (years) } \\
\hline$<65$ & $551(71.5)$ & $220(28.5)$ & 1.240 (0.903 to 1.701$)$ & 0.183 \\
\hline$\geq 65$ & $208(75.6)$ & $67(24.4)$ & 1 & \\
\hline \multicolumn{5}{|l|}{ Surgery history } \\
\hline Yes & $22(61.1)$ & $14(38.9)$ & 1.718 (0.867 to 3.406$)$ & 0.117 \\
\hline No & $737(73.0)$ & $273(27.0)$ & 1 & \\
\hline \multicolumn{5}{|l|}{ Family history } \\
\hline Yes & $63(78.8)$ & $17(21.3)$ & 1 & 0.197 \\
\hline No & $696(72.0)$ & $270(28.0)$ & 1.438 (0.826 to 2.501$)$ & \\
\hline \multicolumn{5}{|l|}{ Employment } \\
\hline Yes & $431(70.5)$ & $180(29.5)$ & 1.280 (0.968 to 1.692$)$ & 0.082 \\
\hline No & $328(75.4)$ & $107(24.6)$ & 1 & \\
\hline \multicolumn{5}{|l|}{ Education level } \\
\hline >High school graduation & $373(70.9)$ & $153(29.1)$ & $1.182(0.900$ to 1.551$)$ & 0.229 \\
\hline$\leq$ High school graduation & $386(74.2)$ & $134(25.8)$ & 1 & \\
\hline \multicolumn{5}{|l|}{ Glaucoma types* } \\
\hline Normal tension & $484(74.3)$ & $167(25.7)$ & $0.802(0.601$ to 1.070$)$ & 0.198 \\
\hline Angle closure & $29(65.9)$ & $15(34.1)$ & 1.202 (0.619 to 2.335$)$ & \\
\hline Open angle & $244(69.9)$ & $105(30.1)$ & 1 & \\
\hline Disease durationt & $\begin{array}{l}13.67 \pm 15.13 \\
12(6,19)\end{array}$ & $\begin{array}{l}13.67 \pm 17.03 \\
12(6,18)\end{array}$ & $1.000(0.991$ to 1.009$)$ & 0.896 \\
\hline \multicolumn{5}{|l|}{ Underlying disease } \\
\hline Yes & $256(70.3)$ & $108(29.7)$ & 1.185 (0.894 to 1.572$)$ & 0.237 \\
\hline No & $503(73.8)$ & $179(26.2)$ & 1 & \\
\hline \multicolumn{5}{|l|}{ Visual field defect severitył } \\
\hline Severe & $150(68.2)$ & $70(31.8)$ & 1.322 (0.941 to 1.856$)$ & 0.267 \\
\hline Moderate & $138(73.0)$ & $51(27.0)$ & $1.047(0.722$ to 1.518$)$ & \\
\hline Mild & $422(73.9)$ & $149(26.1)$ & 1 & \\
\hline
\end{tabular}

symptoms. However, this study result did not show the difference in medication adherence by types of glaucoma. It may have been difficult to detect the significant difference in patients with different glaucoma types given this study include just few angleclosure patients $(4.2 \%, 44$ patients).

This study was a large-scale observational study, in which $>1000$ patients with glaucoma from nationwide medical institutions were enrolled; thus, it provides epidemiological data representative of Korean population with glaucoma. Therefore, the study results can be used to help understand the characteristics and treatment patterns of patients with glaucoma in real hospital settings. Furthermore, considering that this study targeted patients whose duration of treatment was relatively short (patients with a treatment period of at least 1 month but $<2$ years), it can be a good source to reinforce treatment strategies for long-term disease management as it disclosed patients' features in the early stages of disease management. In addition, the associated factors affecting non-adherence to administration of eye-drops were identified, so 
Table 4 Medication non-adherence according to treatment patterns

\begin{tabular}{|c|c|c|c|c|}
\hline Variables & Adherent $(n=759)$ & Non-adherent $(\mathrm{n}=287)$ & OR $(95 \% \mathrm{Cl})$ & p Value \\
\hline \multicolumn{5}{|l|}{ Treatment types } \\
\hline PGA monotherapy* (ref.) & $352(77.4)$ & $103(22.6)$ & 1 & 0.005 \\
\hline Non-PGA monotherapy & $56(63.6)$ & $32(36.4)$ & 1.953 (1.200 to 3.177$)$ & \\
\hline Any combination therapyt & $351(69.8)$ & $152(30.2)$ & $1.480(1.107$ to 1.979$)$ & \\
\hline Prescribed daily number of instillationt & $\begin{array}{l}1.82 \pm 1.04 \\
2(1,2)\end{array}$ & $\begin{array}{l}2.22 \pm 1.38 \\
2(1,3)\end{array}$ & 1.321 (1.182 to 1.477$)$ & $<0.001$ \\
\hline Number of eye-dropst & $\begin{array}{l}1.2 \pm 0.5 \\
1(1,1)\end{array}$ & $\begin{array}{l}1.4 \pm 0.7 \\
1(1,2)\end{array}$ & 1.603 (1.287 to 1.995$)$ & $<0.001$ \\
\hline \multicolumn{5}{|l|}{ Helper/assistant } \\
\hline Yes & $136(75.6)$ & $44(24.4)$ & 1 & 0.329 \\
\hline No & $622(72.0)$ & $424(28.0)$ & $1.203(0.830$ to 1.743$)$ & \\
\hline $\begin{array}{l}\text { Data were presented as } n(\%) \text {. } \\
\text { *Only one drug class in use. } \\
\text { tMore than two drug classes in use. } \\
\text { †Mean } \pm S D \text {, median (first quartile, third qua } \\
\text { PGA, prostaglandin. }\end{array}$ & hitney U test. & & & \\
\hline
\end{tabular}

Table 5 Medication non-adherence according to patients' characteristics and treatment patterns

\begin{tabular}{ll}
\hline Variables & OR $(95 \% \mathrm{Cl})$ \\
\hline Male (ref. female) & $1.466(1.106$ to 1.943$)$ \\
Age $<65$ (ref. age $\geq 65)$ & $1.293(0.934$ to 1.788$)$ \\
Daily number of instillation & $1.328(1.186$ to 1.487$)$
\end{tabular}

Adjusted: sex, age.

Backward elimination; $p=0.753$ by Hosmer-Lemeshow test.

the study results can be used to establish a strong foundation to develop strategies to improve glaucoma management through enhancing medication adherence.

Nevertheless, there are some limitations to this study. Medication adherence was evaluated by calculating the number of days that the patient missed doses of eye-drops during the previous 7 days through a self-reported questionnaire. Hence, there is a possibility of reporting error resulted by recall bias of responders. This is a fundamental limitation of using selfreported questionnaires, despite which they are widely used in many epidemiological studies. Moreover, it is somewhat complicated to identify direct causal relationships between medication adherence and characteristics and habits of administration of the patients because of the cross-sectional nature of this study. Another problem limitation is that the level of patients' knowledge of the disease, which is thought to greatly influence adherence, was not evaluated. On the other hand, these study results are still promising in terms of observing the risk factors, that is, males and increased number of daily instillation to nonadherence from a large number of patients.

Nonetheless, considering that this study targeted a large number of patients, the results are thought to be significant in that it found that the risk of non-adherence was increased in males, and, furthermore, that non-adherence increased with frequency of topical administration of eye-drops, regardless of the level of patient knowledge.

In conclusion, the proportion of patients who were adherent to glaucoma medications in South Korea was about 70\%, which is considered to be relatively good. However, remaining 30\% were still non-adherent to glaucoma therapy, and the nonadherent rate of glaucoma medication was greater in males and when the prescribed frequency of administration was increased, so special attention should be paid to those patient populations.

\author{
Author affiliations \\ ${ }^{1}$ Institute of Vision Research, Department of Ophthalmology, Yonsei University \\ College of Medicine, Seoul, Republic of Korea \\ ${ }^{2}$ Department of Ophthalmology, Seoul National University Hospital, Seoul, Republic \\ of Korea \\ ${ }^{3}$ Ajou University School of Medicine, Suwon, Republic of Korea \\ ${ }^{4}$ Seoul St. Mary's Hospital, The Catholic University of Korea, Seoul, Republic of \\ Korea \\ ${ }^{5}$ Department of Ophthalmology, Yeungnam University College of Medicine, Daegu, \\ Republic of Korea \\ ${ }^{6}$ Sungmo Eye Hospital, Busan, Republic of Korea \\ ${ }^{7}$ Department of Ophthalmology, Sungkyunkwan University School of Medicine, \\ Kangbuk Samsung Hospital, Seoul, Republic of Korea \\ ${ }^{8}$ Kong Eye Clinic, Seoul, Republic of Korea \\ ${ }^{9}$ Seoul National University Bundang Hospital, Gyeonggi-do, Republic of Korea \\ ${ }^{10}$ Korea University Guro Hospital, Seoul, Republic of Korea \\ ${ }^{11}$ Pusan National University Hospital, Busan, Republic of Korea \\ ${ }^{12}$ Chonnam National University Medical School \& Hospital, Gwangju, Republic of \\ Korea \\ ${ }^{13}$ Kim's Eye Hospital, Seoul, Republic of Korea \\ ${ }^{14}$ Asan Medical Center, University of Ulsan College of Medicine, Seoul, Republic of \\ Korea \\ ${ }^{15}$ Korea University Anam Hospital, Seoul, Republic of Korea \\ ${ }^{16}$ Pfizer Pharmaceutical Korea Limited, Seoul, Republic of Korea
}

Contributors All authors have made substantive intellectual contributions in the study, including study design, data acquisition and/or the analysis or interpretation of data and final review of the manuscript.

Funding This study was sponsored by Pfizer Pharmaceuticals Korea.

Competing interests None.

Patient consent Obtained.

Ethics approval This study protocol was approved by institutional review boards in each medical institution involved in this study.

Provenance and peer review Not commissioned; internally peer reviewed.

Open Access This is an Open Access article distributed in accordance with the Creative Commons Attribution Non Commercial (CC BY-NC 4.0) license, which permits others to distribute, remix, adapt, build upon this work non-commercially, and license their derivative works on different terms, provided the original work is properly cited and the use is non-commercial. See: http://creativecommons.org/ licenses/by-nc/4.0/

\section{REFERENCES}

1 Quigley HA, Broman AT. The number of people with glaucoma worldwide in 2010 and 2020. Br J Ophthalmol 2006;90:262-7.

2 National Health Insurance Institute. 400 thousands glaucoma patients in 2009, two-fold increase in seven years. National Health Insurance press release.18 April 2011 
3 Stamper RL, Liberman MF, Drake MV. Becker-Shaffer's diagnosis and therapy of the glaucomas. 8th edn. Mosby: Elsevier, 2009.

4 Kass MA, Heuer DK, Higginbotham EJ, et al. The Ocular Hypertension Treatment Study: a randomized trial determines that topical ocular hypotensive medication delays or prevents the onset of primary open-angle glaucoma. Arch Ophthalmol 2002;120:701-13.

5 Nordstrom BL, Friedman DS, Mozaffari E, et al. Persistence and adherence with topical glaucoma therapy. Am J Ophthalmol 2005;140:598-606.

6 SEAGIG. Asia Pacific Glaucoma Guidelines. 2nd ed. South East Asia Glaucoma Interest South East Asia Glaucoma Interest Group. Scientific Communications International Limited, Hong Kong. 2008. http://www.icoph.org/dynamic/ attachments/resources/asia-pacific_glaucoma_guidelines.pdf.

7 Taylor SA, Galbraith SM, Mills RP. Causes of non-compliance with drug regimens in glaucoma patients: a qualitative study. J Ocul Pharmacol Ther 2002;18:401-9.
8 Sleath $B$, Robin AL, Covert D, et al. Patient-reported behavior and problems in using glaucoma medications. Ophthalmology 2006;113:431-6.

9 Kosoko O, Quigley HA, Vitale S, et al. Risk factors for noncompliance with glaucoma follow-up visits in residents' eye clinic. Ophthalmology 1998;105:2105-11.

10 Patel SC, Spaeth GL. Compliance in patients prescribed eyedrops for glaucoma. Ophthalmic Surg 1995;26:233-6.

11 Busche S, Gramer E. Improved eyedrop administration and compliance in glaucoma patients: A clinical study. Klin Monbl Augenheilkd 1997;211:257-62.

12 Park MH, Kang KD, Moon J; Korean Glaucoma Compliance Study Group. Noncompliance with glaucoma medication in Korean patients: a multicenter qualitative study. Jpn J Ophthalmol 2013;57:47-56.

13 Martin BC, Wiley-Exley EK, Richards $S$, et al. Contrasting measures of adherence with simple drug use, medication switching, and therapeutic duplication. Ann Pharmacother 2009;41:36-44. 